Chance M L. et al. (1978) Ann Trop Med Parasitol; 72: $533-$ 542

Crocker P R, Blackwell J M and Bradley D J. (1984) Infect Immunol; 43: 1033-1040.

GORCZYNSKI R M. (1985) Cell Immunol; 94: 11-20.

GORCZYNSKI R M and MACRAE S. (1982) Cell Immunol; 67: 74-89.

Handman E and Mitchell G F. (1985) Proc Natl Acad Sci $U S A ; 82: 5910-5914$.

Howard J G, HALE C and Liew F Y. (1981) J Exp Med; 153: 557-568.

HOWARD J G. et al. (1982) J Immunol; 129: 2206-2210.

LIEW F Y. (in press) In: Host Resistance Mechanisms.

Rockefeller Univ. Press.

Manson-BaHr P E C. (1961) Trans R Soc Trop Med Hyg; 55: 550-555.

MAYRINK W. (1985) Ann Trop Med Parasitol; 79: 259-269

PReston P M and Dumonde D C. (1976) Clin Exp Immunol; 23: 126-138.

Rezai H R, Farrel J and Soulsby E L. (1980) Clin Exp Immunol; 40: 508-514.

SACKS D L. et al. (1984) I Immunol; 132: 2072-2077.

STEINBERger A. (1984) Exp Parasitol; 58: 223-229.

Wenyon C M. (1911) Parasitology; 4: 273-344.

\section{Part II.III Leishmania Antigen Presentation and $T$ Cells}

\section{R S Bray}

\section{Department of Pure and Applied Biology Imperial College of Science and Technology London SW7}

The method by which antigen is presented to the Tcell domain by antigen presenting cells is obviously critical to the T-cell response where T-cells of the same phenotype are capable of expressing both helper and suppressor functions. There is evidence that the configuration of the antigenic molecule on presentation can alter the $\mathrm{T}$-cell response.

In our hands the only effective antigen presenting cell in vitro is the macrophage although spleen cells have been effective with others. While whole soluble antigen is an effective inducer of T-cell proliferation, the fractions coming off first from a Sephadex 100 column contain most of the effective stimulatory antigens. Following infection in $\mathrm{CBA} / \mathrm{Ca}$ mice the antigen still present in lymph node cells is sufficient to initiate primary T-cell proliferation.

In our hands colonies of T-cells can be transferred and kept alive for several weeks but colonies do not continue to proliferate beyond the initial growth despite the presence of interleukin II.
Part III. Leishmania Biochemistry and Chemotherapy

$$
\text { Chaired by Dr D L Goodwin }
$$

Part III.I Antileishmanial Chemotherapy Reviewed

$$
\text { R A Neal }
$$

\section{London School of Hygiene and Tropical Medicine St Albans, Herts A14 OXQ.}

\section{Introduction}

The early development of chemotherapy was $\stackrel{\Phi}{\varrho}$ stimulated by the realization that some dyes such as methylene blue were able preferentially to stain $\vec{\circ}$ particular cells and this idea developed into the concept of chemical substances which could unite with and $\vec{\omega}$ inhibit parasitic agents of disease - the so-called magic $\stackrel{\rho}{S}$ bullet theory of Paul Erhlich. There was next a quantum $\stackrel{\vec{D}}{\overrightarrow{7}}$ leap to the use of arsenic compounds against African trypanosomes, particularly a supposedly less toxic $\vec{\omega}$ compound atoxyl, originally prepared by Bechamp in 1863 and used clinically at that time for treatment of skin $\underset{\omega}{\omega}$ conditions and anæmia.

A smaller conceptual leap in thinking was then to the use of antimony compounds such as tartar emetic which like the arsenic compounds was also trypanocidal. Tle first use of antimonials in leishmaniasis in man credited to Vianni who used tartar emetic in Brazil treat a patient with cutaneous leishmaniasis. Since the time other antimonial drugs have been studied such as $\vec{\varphi}$ urea stibamine, sodium antimony tartrate, stibophe anthiomaline, stibamine, neostibophen, neostan sodium stibogluconate, meglumine antimoniate a many others.

From about 1950 it became apparent that the pentavalent compounds were much less toxic clinically $\frac{\varnothing}{\varnothing}$ that the trivalent antimonials, and today treatment is $\varrho$ confined primarily to two pentavalent antimonials, $\overrightarrow{\overrightarrow{0}}$ sodium stibogluconate and meglumine antimoniate. $\exists$ The organo derivatives of oxo-antimony anions are illdefined and exhibit various degrees of polymerisation which makes complete chemical quality control of the products impracticable. However, modern antimonial drugs, with standardization of conditions of synthesis, chemical analysis of pentavalent antimony combined $\overrightarrow{\mathbb{D}}$ with biological control of toxicity and efficacy, give the $\stackrel{\varrho}{\rightleftarrows}$ best possible standard compound. Sodium? stibogluconate in aqueous solution has a mean 3 molecular weight of about 400 .

\section{The Clinical Situation}

From the clinical point of view, the drugs currently available for treatment of all forms of leishmaniasis are $\frac{7}{0}$ the two pentavalent antimonial compounds, sodium stibogluconate and meglumine antimoniate, the polyene $\mathcal{N}$ antibiotic amphotercin B used primarily as second line $N$ treatment for Latin-American cutaneous leishmaniasis N 